\title{
In memory of Dr. Kimberly S. Young: The story of a pioneer
}

\author{
MATTHIAS BRAND ${ }^{1,2} *$ and MARC N. POTENZA ${ }^{3,4,5}$ \\ ${ }^{1}$ General Psychology: Cognition and Center for Behavioral Addiction Research (CeBAR), University of Duisburg-Essen, \\ Duisburg, Germany \\ ${ }^{2}$ Erwin L. Hahn Institute for Magnetic Resonance Imaging, Essen, Germany \\ ${ }^{3}$ Departments of Psychiatry, Neuroscience and Child Study, Yale University School of Medicine, New Haven, CT, USA \\ ${ }^{4}$ Connecticut Council on Problem Gambling, Wethersfield, CT, USA \\ ${ }^{5}$ Connecticut Mental Health Center, New Haven, CT, USA
}

(Received: March 15, 2019; accepted: March 15, 2019)

Dr. Kimberly S. Young passed away on February 28, 2019. She was 53 years of age when she died after a three-and-ahalf-year battle with cancer. She will be missed by many.

Dr. Young graduated in 1988 with a bachelor's degree in Business Administration from the University at Buffalo. Subsequently, she received a master's degree in Clinical Psychology from the University of Pennsylvania and completed her doctorate in Clinical Psychology in 1994. After having several post-doctoral positions at the Universities of Rochester and Pittsburgh/Bradford, she became a professor at St. Bonaventure University in Olean in 2002. She joined the Jandoli School of Communication at St. Bonaventure University in 2006 and became the Director of the Master's Program of Strategic Leadership.

As early as 1995 , shortly after completing her $\mathrm{PhD}$, she started publishing articles in international peer-reviewed journals on the topic of Internet addiction. In the same year, she also established the Center for Internet Addiction. She was one of the first researchers interested in understanding the psychological mechanisms underlying problematic or addictive use of the Internet. Dr. Young developed the Internet Addiction Test (IAT), a 20-item scale for assessing features of Internet addiction. The IAT has been translated into various languages and used in several studies worldwide. With her comprehensive publications in books and articles, she became a pioneer of the rapidly growing and changing field of Internet addiction research. She was also dedicated to transferring emerging knowledge on Internet addiction into clinical practice. She was committed not only to diagnosing individuals with Internet addiction, but also to providing and optimizing treatment. Inspired by cognitivebehavioral therapy (CBT) used in the treatment of other behaviors and disorders, she developed a CBT model for treating people with Internet addiction, which she named CBT-IA. It has been, and is still, a foundation and inspiration for many new developments to follow. She also founded the first US-based inpatient hospital clinic for Internet addiction at the Bradford Regional Medical Center.

\footnotetext{
* Corresponding author: Prof. Dr. Matthias Brand; General Psychology: Cognition and Center for Behavioral Addiction Research (CeBAR), University of Duisburg-Essen, Forsthausweg 2, 47057 Duisburg, Germany; Phone: +49 203 3792541; Fax: +49 203 3791846; E-mail: matthias.brand@uni-due.de
}

This is an open-access article distributed under the terms of the Creative Commons Attribution-NonCommercial 4.0 International License, which permits unrestricted use, distribution, and reproduction in any medium for non-commercial purposes, provided the original author and source are credited, a link to the CC License is provided, and changes - if any - are indicated. 
Later in her career, she also developed prevention programs to help parents to support their children in using the Internet in healthy and functional ways.

Dr. Young was a member of editorial boards of several journals, including the Journal of Behavioral Addictions, and she was a member of the American Psychological Association. She was invited as a keynote speaker to several international conferences, for example, the International Conference on Behavioral Addictions in Budapest (Hungary), the Conference on Digital Culture in Seoul (Korea), and the International Congress on Internet Addiction Disorders in Milan (Italy).

Dr. Young published many articles that have influenced the field of Internet addiction research and treatment. She also published several books and book chapters on media use and Internet addiction that have targeted broad audiences. In 1998, her book "Caught in the Net" was a bestseller that has been translated into many languages. She also published creative fiction including her novel in 2013 entitled "The Eighth Wonder," which is a love story. In her last year, Kimberly published her memoirs entitled, "Building Mountains from Dust." In this book, she describes her battle with cancer and the difficult times she encountered when her beloved husband for almost 20 years, James (Jim) O'Mara, passed away in February of 2017.

In her publications, presentations, and media interviews, she provided a voice for individuals who struggled with problematic use of the Internet, long before the first steps were made to officially recognize types and patterns of Internet use as psychiatric disorders. She clearly has her own place in history. Collaborating with her was a gift. Her death at an early age is tragic. She will be missed immensely and will not be forgotten as a pioneer and as an amiable, creative, and passionate person. Her impact on research and society will persist.

Funding sources: There is no funding associated with this manuscript.

Authors' contribution: Drs. MB and MNP worked collaboratively on this manuscript. MB completed the first draft and MNP provided feedback and added additional content.
Conflict of interest: Drs. MB and MNP declare no conflict of interest to disclose related to this manuscript.

\section{SEMINAL AND/OR IMPORTANT PUBLICATIONS BY DR. KIMBERLY S. YOUNG}

Young, K. S. (1996). Addictive use of the Internet: A case that breaks the stereotype. Psychological Reports, 79(3), 899-902. doi:10.2466/pr0.1996.79.3.899

Young, K. S. (1998a). Caught in the net: How to recognize the signs of Internet addiction - And a winning strategy for recovery. New York, NY: John Wiley \& Sons.

Young, K. S. (1998b). Internet addiction: The emergence of a new clinical disorder. CyberPsychology \& Behavior, 1(3), 237-244. doi:10.1089/cpb.1998.1.237

Young, K. S. (2004). Internet addiction: A new clinical phenomenon and its consequences. American Behavioral Scientist, 48(4), 402-415.doi:10.1177/0002764204270278

Young, K. S. (2007). Cognitive behavior therapy with Internet addicts: Treatment outcomes and implications. CyberPsychology \& Behavior, 10(5), 671-679. doi:10.1089/cpb.2007. 9971

Young, K. S. (2008). Internet sex addiction: Risk factors, stages of development, and treatment. American Behavioral Scientist, 52(1), 21-37. doi:10.1177/0002764208321339

Young, K. S. (2009). Internet addiction: Diagnosis and treatment considerations. Journal of Contemporary Psychotherapy, 39(4), 241-246. doi:10.1007/s10879-009-9120-x

Young, K. S. (2011). CBT-IA: The first treatment model to address Internet addiction. Journal of Cognitive Therapy, 25, 304-312. doi:10.1891/0889-8391.25.4.304

Young, K. S. (2013). Treatment outcomes using CBT-IA with Internet-addicted patients. Journal of Behavioral Addictions, 2(4), 209-215. doi:10.1556/JBA.2.2013.4.3

Young, K. S., \& Brand, M. (2017). Merging theoretical models and therapy approaches in the context of Internet gaming disorder: A personal perspective. Frontiers in Psychology: Psychopathology, 8, 1853. doi:10.3389/fpsyg.2017.01853

Young, K. S., Pistner, M., O’Mara, J., \& Buchanan, J. (1999). Cyber disorders: The mental health concern for the new millennium. CyberPsychology \& Behavior, 2(5), 475-479. doi:10.1089/cpb.1999.2.475 